\title{
Withdrawal of anticancer therapy in advanced disease: a systematic literature review
}

G. Clarke ${ }^{1 *}$, S. Johnston ${ }^{2}$ P. Corrie ${ }^{3}$, I. Kuhn ${ }^{4}$ and S. Barclay ${ }^{1}$

\begin{abstract}
Background: Current guidelines set out when to start anticancer treatments, but not when to stop as the end of life approaches. Conventional cytotoxic agents are administered intravenously and have major life-threatening toxicities. Newer drugs include molecular targeted agents (MTAs), in particular, small molecule kinase-inhibitors (KIs), which are administered orally. These have fewer life-threatening toxicities, and are increasingly used to palliate advanced cancer, generally offering additional months of survival benefit. MTAs are substantially more expensive, between $£ 2-8 \mathrm{~K}$ per month, and perceived as easier to start than stop.

Methods: A systematic review of decision-making concerning the withdrawal of anticancer drugs towards the end of life within clinical practice, with a particular focus on MTAs. Nine electronic databases searched. PRISMA guidelines followed.

Results: Forty-two studies included. How are decisions made? Decision-making was shared and ongoing, including stopping, starting and trying different treatments. Oncologists often experienced 'professional role dissonance' between their self-perception as 'treaters', and talking about end of life care. Why are decisions made? Clinical factors: disease progression, worsening functional status, treatment side-effects. Non-clinical factors: physicians' personal experience, values, emotions. Some patients continued treatment to maintain 'hope', often reflecting limited understanding of palliative goals. When are decisions made? Limited evidence reveals patients' decisions based upon quality of life benefits. Clinicians found timing withdrawal particularly challenging. Who makes the decisions? Decisions were based within physician-patient interaction.

Conclusions: Oncologists report that decisions around stopping chemotherapy treatment are challenging, with limited evidence-based guidance outside of clinical trial protocols. The increasing availability of oral MTAs is transforming the management of incurable cancer; blurring boundaries between active treatment and palliative care. No studies specifically addressing decision-making around stopping MTAs in clinical practice were identified. There is a need to develop an evidence base to support physicians and patients with decision-making around the withdrawal of these high cost treatments.
\end{abstract}

Keywords: Molecular targeted agents, Treatment decision-making, End of life, Palliative care

\footnotetext{
* Correspondence: gcc29@medschl.cam.ac.uk

${ }^{1}$ Primary Care Unit, Department of Public Health and Primary Care, University

of Cambridge, Cambridge, United Kingdom

Full list of author information is available at the end of the article
} 


\section{Background}

Decision-making around starting and stopping treatment in advanced cancer is challenging for all concerned; patients, families and healthcare professionals alike. Appropriately timed cessation of treatment is an internationally recognised cancer treatment quality indicator [1-4], yet recent years have seen a trend towards continuing treatment until close to the end of life [5-7], at times within weeks of death $[5,7,8]$. In the UK, following a national audit of morbidity and mortality associated with chemotherapy, death within 30 days of receiving chemotherapy is now an accepted standard with an expectation that continuing chemotherapy in the last month of life is futile [9]. Recent research has demonstrated palliative cytotoxic chemotherapy at the end of life to be associated with a host of adverse outcomes including cardiopulmonary resuscitation, death in intensive care unit, place of death less likely to be at home or in preferred place and late hospice referral, as well as no survival benefit $[10,11]$.

Increased prescribing of cancer treatments over longer periods of time has been linked to availability of a plethora of new anti-cancer drugs, particularly the molecular targeted anticancer agents (MTAs) such as small molecule kinase inhibitors (KIs) $[12,13]$. MTAs have been shown to improve outcomes in a variety of advanced malignancies, including chronic myeloid leukaemia, acute myeloid leukaemia, non-Hodgkin lymphomas, gastrointestinal stromal tumours (GIST), melanoma, renal and breast cancers [12, 14-16]. Notably, kinase-inhibitors (KIs) have improved survival in traditionally chemoresistant cancers, including advanced non-small cell lung cancer (NSCLC) [17-19], melanoma [20, 21] and renal cell cancer $[22,23]$.

Over recent years, MTAs have therefore transformed cancer management and their number is set to continue to increase over time $[12,14]$. In addition to survival gains, oral MTAs allow for flexibility in care-planning, since patients administer their own treatment at home, avoiding hospital visits [24]. Although not without sideeffects, MTA-induced toxicities are rarely life threatening with significantly lower rates of myelosuppression compared with conventional cytotoxic chemotherapy [14].

Eligibility to access MTAs is well defined by drug licensing indications, but stopping treatment, by contrast, is very different. RECIST (Response Evaluation Criteria In Solid Tumours) criteria are widely used within clinical trials for stopping treatment, based on proportional increase in tumour measurements during therapy [25]. Outside of trials, decision-making is far less tightly controlled and subjective endpoints influence decision making. Furthermore, recent evidence suggests that MTAs may improve survival despite RECIST evidence of measurable disease progression [26, 27]. Continued treatment with MTAs despite tumour growth is also being influenced by reports of rebound progression or "disease flare" on stopping therapy $[20,21,28,29]$. There is also growing evidence of survival benefit from MTA re-challenge after a period off treatment in Non-Small Cell Lung Cancer (NSCLC) [28], and Gastrointestinal Stromal Tumour (GIST) [30] and renal cell cancer [31].

In most cases, the survival benefits of MTAs when treating patients with advanced solid tumours is measured in months rather than years [12, 14-16]. Costing between $£ 2000$ and $£ 8000$ per month, they impose considerable pressure on individuals and financially constrained healthcare systems. [32] There is therefore a strong health economic argument to ensure that guidance is available to support discontinuation of MTAs for reasons of futility. A systematic review of the literature was therefore undertaken, to identify current knowledge concerning decision-making in clinical practice to withdraw anticancer treatment in patients with advanced solid tumours.

\section{Aims}

To examine decision-making concerning the withdrawal of anticancer treatments in patients with advanced solid tumours outside of clinical trials, with particular regard to MTAs:

(1) How are these decisions made?

(2) Why are these decisions made?

(3) Who makes these decisions?

(4) When are these decisions made?

\section{Methods}

We undertook a systematic search of the international literature, utilising a thematic approach to analysis [33] and a narrative synthesis for presenting the findings [34].

\section{Search strategy and selection criteria}

Nine electronic databases (AMED (Allied and Complementary Medicine Database), ASSIA (Applied Social Sciences Index and Abstracts), BNI (British Nursing Index), CINAHL (Cumulative Index of Nursing and Allied Health Literature), Embase, MEDLINE, PsychINFO, SSCI (Social Sciences Citation Index), Cochrane Library) were searched for papers published between January 2003 and August 2013, using search strategies developed in conjunction with a professional librarian (IK) (Fig. 1). The grey literature was searched using the NHS evidence database, policy institute websites and charity and healthcare websites. Hand-searches of Lancet Oncology, British Journal of Cancer, Annals of Oncology and Journal of Clinical Oncology were undertaken, with reference and citation searches of all included papers. PRISMA guidelines were followed [35].

Inclusion criteria: studies of decision-making concerning cessation or continuation of oral or parenteral treatments 


\begin{tabular}{|c|c|}
\hline Database & AMED \\
\hline $\begin{array}{l}\text { Search } \\
\text { terms }\end{array}$ & $\begin{array}{l}\text { Antineoplastic OR Cytotoxi* OR anticancer OR "anti cancer" OR anti-cancer OR } \\
\text { chemotherapy OR anticarcinogenic OR anti-carcinogenic OR "anti carcinogenic" OR } \\
\text { "monoclonal antibod*" OR "tyrosine-kinase inhibitor*" OR hormon* OR drug* OR } \\
\text { enteral OR parenteral OR IV OR oral } \\
\text { AND } \\
\text { neoplasm* OR cancer* OR metastas* OR carcinoma OR sarcoma OR tumour* OR } \\
\text { tumor* OR leukemia OR lymphoma OR myeloma } \\
\text { AND } \\
\text { cessation OR withdraw* OR withdrew* OR discontinu* OR halt* OR stop* OR drop-out } \\
\text { OR dropout OR "drop out" OR "dropped out" OR "RECIST" OR palliat* OR decision* OR } \\
\text { palliative OR decision-making OR "decision making" OR choice OR "end of life" OR EOL } \\
\text { OR EOLC OR "care planning" OR care-planning OR "advanced planning" OR } \\
\text { conversation* OR side-effect* OR "side effect*" OR experience* OR "quality of life" OR } \\
\text { QOL OR futil* OR terminal OR "disease progression" }\end{array}$ \\
\hline Limits & $\begin{array}{l}\text { Publication year } 2003 \text { - Aug } 2014 \\
\text { Title/Abstract }\end{array}$ \\
\hline Results & 286 \\
\hline
\end{tabular}

Fig. 1 Cross-tabulation illustrating example search terms and strategy for an electronic database

for advanced malignant disease; qualitative or quantitative research methods; treatments being used in clinical practice; abstract or full paper available in English language. Studies investigating MTAs were particularly sought. Exclusion criteria: children under age 18, discussion or opinion pieces containing no new empirical data, steroids, bisphosphonates, treatment with radiation therapy only and clinical trial data.

\section{Data extraction, quality evaluation and analysis}

Abstracts were screened by three authors (GC: social scientist, SJ: medical oncologist, SB: GP and palliative specialist) and full papers screened by GC and SJ who also independently assessed study quality using Gough's Weight of Evidence framework [36]. Studies rated 'high' were given greater weight. A qualitative sensitivity analysis was performed [37]. We excluded studies rated as 'low quality' and assessed whether the findings were altered by this exclusion. Firstly, we examined whether any of the analytics themes were lost; and secondly we examined whether any of the 'depth' of the findings was lost. Data was entered into a review-specific data extraction form and then into NVivo9 for a narrative synthesis using a "thematic approach" [33].

\section{Ethics}

This study did not require approval by an ethics committee as it is a systematic literature review of previously published work. PRISMA (Preferred Reporting Items for Systematic Reviews and Meta-Analyses) guidelines for a systematic review were followed [35].

\section{Results}

Searches yielded 8368 citations, 371 abstracts and 81 full papers were assessed. A total of 42 papers met the inclusion criteria and were included in the final analysis. Fig. 2 summarises this process.

Numbers of included papers are indicated in square brackets [ ]. Thirty-two papers (76 \%) investigated decisions to stop treatment for a range of solid and haematological cancers. Ten (24 \%) examined specific malignancies: lung [4], pancreas [2] and 1 each for ovarian, breast, lung and colorectal, colorectal and breast cancers. Most examined chemotherapy in general rather than specific drug regimens. Two papers discussed the use of MTAs in the final months of life [38, 39], and a further three briefly commented on MTAs [40-42]: none described decision making processes concerning stopping MTAs close to the end of life. Papers came from 14 different countries, some studies comprised evidence from multiple countries: USA [15], Netherlands [5], UK [4], Japan [3], 2 each from New Zealand, Canada, Italy and Sweden and 1 each from Germany, Australia, Taiwan, Belgium, Korea, UK with USA, and Australia with Israel. Twenty-four of these studies contained primarily qualitative data, and 18 contained primarily quantitative data. Additional file 1 [see Additional file 2] summarises the main characteristics of included studies. The sensitivity analysis revealed that removing studies rated as low quality did not alter the overall findings; no themes or topics were lost, and only a small amount of the 'depth' or 'thickness' of the findings was lost. 


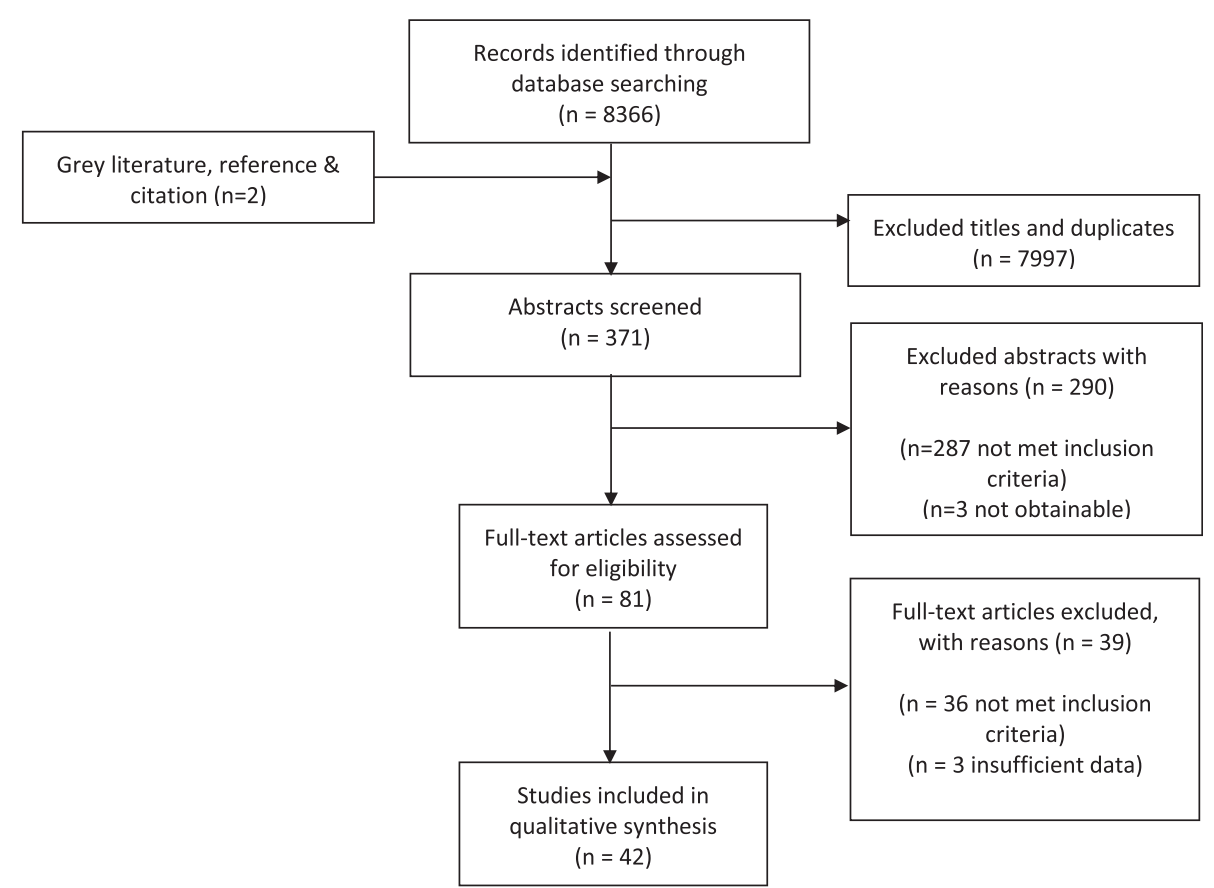

Fig. 2 Flow diagram illustrating systematic search process

\section{(1) How are decisions made?}

The process of treatment withdrawal was described as a shared progression of many different conversations rather than a one-off decision [11, 38, 40, 42-50]. It involved a trajectory of repeated reassessments and trying different treatment options [13, 38, 40, 42-50], including treatment breaks before starting subsequent new regimens $[4,38,40,42,50]$. MTAs contribute to this process by providing more options before cessation of all treatment [2, 38, 39]. Decisions about withdrawing treatment were described as an integral part of patient care [45], strongly influenced by patients' views and wishes [51]. Collusion in continuing inappropriate treatment may occur unless both oncologist and patient are ready to discuss stopping treatment and both acknowledge that the end of life is near [38].

Oncologists commonly report finding discussions about stopping treatment difficult $[6,38,42,44,46,50,52]$ and emotionally challenging $[3,38,49,52]$.

"What I like least [about my job] is giving people bad news. It's just terrible. It's just horrible. It's so sad...It's just horribly sad." (Oncologist) [38]

Clinicians reported that discussions around stopping treatment are commonplace and challenging, with a limited evidence base outside of clinical trial protocols available for guidance [38]. The 'grey area' in which patients want another line of chemotherapy and their condition could permit it, but on the balance benefits and burdens it would be inadvisable, is particularly challenging [52]. The process of withdrawing treatment involves switching role from that of an "advocate" for curative or disease modifying treatments to a supportive "counselling" role for palliative, end of life care [49]. This role switch may create "role dissonance" for oncologists who often perceive themselves as "treaters" who "do something" [38]. Clinicians may become "stuck" on an "institutional script for treatment" [46] which prevents them from discussing alternative supportive interventions, "watchful waiting" [53], or discussions concerning death and dying $[46,54]$.

Stopping treatment may be raised by clinicians as a new direction of treatment in which the patient's emotions are directly addressed [42], or by presenting it as a "biological fact" that leaves little room for discussion:

\footnotetext{
"And so we started you off with the standard treatment. . . .We didn't quite see what we wanted with that, we moved on to something else. One thing I just want to make sure you realize is that we don't save our best weapons for the end. We use them up front. So the chances of you responding to other agents, are even less than the chances were with the two other regimens you've already gotten". (Oncologist talking to patient) [42]
}

Some oncologists describe a "contemplation stage" during which evidence is gathered concerning disease progression and treatment options and consideration given on how to present this to the patient $[38,49,52]$. 
Few studies addressed the involvement of patients and their supporters in treatment cessation decisions. Oncologists expressed the view that patients need to be beginning to accept their terminal status before they can be ready to consider stopping treatment $[3,44,47,51]$, for some this acceptance may not happen until very close to death [44]. Patients with greater experience of treatment may be more confident about negotiating treatment options and being involved in decisions [48]. Those with strong belief in the effectiveness of the treatment may have it continued longer [55]. Some patients withdraw from the decision-making process as their disease progresses and a surrogate decision-maker takes over [51, 53]. A perception that doctors do not wish to involve family members in discussions may cause considerable distress [56].

\section{(2) Why are decisions made?}

Decisions to stop treatment are complex and multifaceted, with four major factors identified from the literature.

(a) Disease and clinical factors: Key factors in decisions to stop treatment included worsening patient condition or functional status $[10,38,43,44,49,52,55,57-60]$ disease progression or advanced stage disease $[9,38,40,43,44$, $47,49,52,57,60]$ and treatment side effects $[7,38,49,52$, 55, 59-61]. Patients who received their diagnosis when only in advanced disease, and patients who had not received treatment earlier in the course of illness for other reasons, often had their therapy extended much longer than patients who had received earlier treatments $[5,38,62-65]$.

The type of cancer influenced treatment decisions $[7,38$, $43,49,60,62,64,66]$. For example, patients with haematological malignancies $[4,38,43,62,63]$, and advanced lung cancers $[2,38,64]$, were more likely to have their treatment continued. Chemo-responsiveness of tumours was reported to be a key factor in decisions to continue treatment $[2,43,66]$, although two population-based studies found no such connection [41, 67]. Six population studies found treatment was more likely to be withdrawn or withheld in older people $[57,58,62,63,67,68]$, although one study found age was not a predictor of discontinuing palliative treatment [60].

(b) Clinician-dependent factors: A range of nonclinical factors influenced decision-making in the face of cancer progression. Clinicians' personal approaches, heavily shaped by their personal perspectives and ethics $[6,38,43,49,52,69,70]$ were significant predictors of whether chemotherapy was continued as disease progressed $[2,57,66]$ Doctors' views of patients' personalities and circumstances also influenced the decision [4, $38,43,49,70]$.

\section{"I think instinctively you feel that this is a young} patient with a young family you need to make even more effort to try and help them live for a bit longer". (Oncologist) [49]

Some doctors reported they would continue treatment within two weeks of death for even a small chance of possible extension of life [39]. Treatment was also more likely to be continued by younger and less experienced doctors $[2,38,43]$, and in the face of uncertainty of clinical benefit $[38,39]$.

"We are poor predictors of prognosis even in these near death time frame and we therefore err on the side of more treatment." (Oncologist) [39]

Treatment was often continued to avoid "taking away hope" $[4,38,49,52,71]$ and when strong relationships have developed with patients [3, 43, 44, 72].

(c) Patient-dependent factors: Hope for the future was an important driver for patients' decision-making [3, $44,47,48]$, although this hope at times reflected poor understanding of the palliative rather than curative aims of treatment $[4,48,72-75]$. When making decisions, patients strive to balance hope and improvements in quality of life, with side-effects and the burdens of treatment $[5,51,55,61,63,68]$. Older patients are more likely to discontinue treatment when approaching the end of life $[8,57,58,62-64,66,67]$, although one study found no such association [60].

(d) Environmental factors: Hospital setting was a key influence on whether or not treatment was continued $[6,38,39,57,60,62,76,77]$. Treatment was more likely to be continued in teaching hospitals [62], and those receiving private treatment in physicians' offices, rather than in general hospital outpatient clinics [77]. Access to and information about palliative care services was associated with stopping treatment $[3,39,57,60]$, as was having a supportive care plan in place [54], although hospice referral was not always associated with treatment discontinuation [54].

Treatment costs also influence these decisions, particularly in health systems where patients have to meet drug costs personally $[3,38,39,77]$. The availability of new MTAs, although expensive, influence decisions to continue treatment as they provide additional options for continuation of treatment $[3,38,39,43]$.

\section{(3) When are decisions made?}

The literature concerning the timing of decisions to withdraw treatment was very limited. Clinicians expressed great difficulty over judging the appropriate time to stop [5, 38, 43, 44, 48, 49], particularly when a patient's condition could justify, but the prognosis was unclear and the benefit of treatment was uncertain [52]. Patients also expressed uncertainty about the 
timing of treatment withdrawal. In one study, all participants unanimously emphasised the difficulty of anticipating the right time to make the decision to stop all treatment [48].

\section{(4) Who makes the decision?}

The majority of studies reporting upon 'who makes the decision, found decision-making was an on-going process based in the interaction between the physician and patient, and sometimes close relatives [8, 38, 40, 43, 45, 48, 49, 52, 73]. However there was mixed evidence upon who in reality was involved in decision-making and who made the final decision. One study reported fewer patients to have been involved in the decision-making process than wanted to be, and that only half of competent patients were involved [78]. In contrast, another study reported family members to believe that the patients' preferences had been followed in $78 \%$ of cases [79]. Nurses often have an important supportive role $[4,43,52,57,61]$, as may the wider multidisciplinary team [49].

A smaller number of studies found decisions were driven by one particular party: four studies found decision-making was patient driven, two of these studies were based in the USA, one was based in The Netherlands and the other in Israel and Australia [39, 44, 51, 52]; in contrast three studies found physicians had the strongest influence, one on these studies was based in the USA, one in New Zealand and one in the Netherlands [43, 52, 71]. The number of studies and the limited high quality evidence on this topic means that no effect by country or continent could be found.

Doctors exerted influence by choosing which options to present to patients [43], and the way in which those options were presented [52]. Some patients preferred not to be involved in the decision-making at all [48], while for others feeling in control was important, even if it was only control of day-to-day decisions $[44,48,80]$.

\section{"I want to be able to have control or say about my illness, whether I think I should take chemo or not. The doctors tried to talk me out of it [her decision to stop treatment], and it's just like, it's MY body. I feel it's not going to do anything for me. It's making me sicker so why do it? I felt that it was important for me to have control over that." (Patient declining chemotherapy in advanced disease) [80].}

\section{Discussion}

Deciding that "enough is enough", that cancer treatment should be stopped in the face of approaching end of life, is one of the most challenging decisions that patients, their families and oncologists have to make. Based on limited published evidence primarily derived from the USA, these decisions appeared to be made over a period of time, in the context of an ongoing and trusting relationship between oncologist and patient, and were largely clinician-guided. Clinical factors such as disease response and progression dominated treatment decisionmaking, with physicians having to weigh up the potential "costs" of the treatment to the patient such as side-effects and toxicities, with potential "benefits" such extended lifespan or giving the patient hope for the future.

The decision to continue or stop cancer chemotherapy has costs associated, both to the patient and the wider health economy. While MTAs have fewer life threatening toxicities than conventional cytotoxic chemotherapy, common toxicities including rash, diarrhoea and interstitial pneumonia generate hospital admissions [81, 82]. Multi-targeted Vascular Endothelial Growth Factor Receptor Tyrosine-Kinase Inhibitors (VEGFR TKIs) are associated with haemorrhage, hypertension, adrenal dysfunction, hypothyroidism and acute coronary syndrome [83]. Some BRAF (B-Raf proto-oncogene, serine/threonine kinase) targeted inhibitors are associated with chronic photosensitivity and risk of skin squamous cell cancers [84]. Many MTAs cause fatigue [14], which may significantly impair quality of life.

However, subtle factors such as clinicians' attitudes and personalities, doctor-patient relationships and relatives' and patients' views strongly influenced decisions. A concern to foster 'hope for the future' was a significant factor for all parties, but at times, this hope was unrealistic, reflected poor understanding of palliative treatments, or arose from physician collusion. These findings show that the nature of the patient-physician relationship is a key part of decision-making concerning the withdrawal of anticancer drugs towards the end of life, and add growing support to the body of knowledge on the importance on 'trust' and 'rapport' in shared healthcare decision-making $[85,86]$.

To our knowledge, this is the first systematic review of decision-making concerning withdrawing anticancer treatments in advanced disease within clinical practice. We used a rigorous and inclusive search strategy to comprehensively search the international literature, including nine electronic databases and grey literature. A broad range of study populations and methodologies were included, incorporating evidence from both qualitative and quantitative studies. Several factors indicate the robustness of the findings: the themes identified were repeated across a large proportion of the studies, despite the heterogeneous contexts and populations; the themes did not vary substantially across different countries; and the sensitivity analysis revealed that removing studies rated as 'low' did not alter the findings of the review.

This review does have several limitations. There is limited high quality evidence: using Gough's weight of evidence framework [36] only nine studies were rated as high quality, 15 as medium and 18 as low quality. Many of the low rated studies had a small sample size or 
limited evidence relevant to the review questions. Higher quality studies were given greater weighting in the thematic analysis, although sensitivity analysis revealed that removing studies rated as 'low' did not alter the findings of the review. The heterogeneous nature of included studies made comparisons difficult; we selected a thematic analysis and narrative synthesis methodology to account for this. Only studies published in English language were included: although the included studies had a wide international range, $38 \%(16 / 42)$ of included papers were from Europe, 36 \% (15/42) from the United States and $12 \%(5 / 42)$ from Asia. Clinical practice may be particularly different in the US where patients may exert pressure to continue treatment and clinicians have personal financial incentives to prolong treatment.

\section{Conclusions}

The advent of molecular targeted agents (MTAs) has brought new benefits as well as challenges to modern cancer therapy, potentially blurring the distinction between active and palliative interventions. Traditionally, disease progression is an indication to stop treatment, but outside of trials, stopping treatment is far more challenging. Furthermore, there is evidence to show that patients receiving oral MTAs continue treatment until closer to death than those receiving intravenous anticancer therapies [38, 39, 41, 69]. While it is generally considered that continuing treatment in the last 30 days of life must be futile from a biomedical perspective, there may be benefit in continuing MTA treatment beyond disease progression [26], particularly given the potential for "tumour flare" on stopping these therapies [26]. It has been suggested that for modern targeted therapies, the definition of disease progression may itself need redefining $[16,27]$. It remains unclear how best to integrate MTAs into modern treatment algorithms [16, 27].

Wider subjective factors clearly influence treatment decision-making and the relative balance of harms and benefits associated with patients, carers and doctors choosing to continue anticancer drugs beyond disease progression has not yet been determined. While MTAs offer real hope for patients with advanced cancers, their considerable financial costs are raising major health economic and ethical concerns in resource-constrained health services across the world. With rising cancer incidence and increasing numbers of patients on MTA treatment across the world, it is important for clinical practice, as well as society as a whole, to have realistic expectations of these new agents. We found no studies which specifically addressed decisions concerning when to stop treatment with MTAs. While the recent development of these agents may in part be responsible for the lack of research, there is clearly a pressing need to develop an evidence-base to allow physicians to weigh up the potential 'costs' and 'benefits' of these treatments and inform optimal decisionmaking associated with stopping MTAs.

\section{Additional file}

Additional file 1: Cross-tabulation illustrating evidence summary of included papers $(N=42)$. (DOCX $48.2 \mathrm{~kb})$

Additional file 2: PRISMA 2009 Checklist. (PDF $91 \mathrm{~kb}$ )

\section{Abbreviations}

MTA: molecular targeted agent; Kl: kinase inhibitor; RECIST: response evaluation criteria in solid tumours; NSCLC: non-small cell lung cancer; GIST: gastrointestinal stromal tumour; VEGFR TKI: vascular endothelial growth factor receptor tyrosine-kinase inhibitors; BRAF: B-Raf proto-oncogene, serine/threonine kinase; PRISMA: preferred reporting items for systematic reviews and metaanalyses; AMED: allied and complementary medicine database; ASSIA: applied social sciences index and abstracts; BNI: British nursing index; CINAHL: cumulative index of nursing and allied health literature; SSCl: social sciences citation index.

\section{Competing interests}

The authors declare they have no competing interests.

\section{Authors' contributions}

The study was designed and led by GC, PC and SB, literature searching undertaken by GC and IK, screening of abstracts and papers and data extraction by GC and SJ, journal hand-searching by GC and synthesis by GC, SJ and SB. All authors have read and approved the manuscript.

\section{Acknowledgements}

This independent research was funded by the National Institute for Health Research (NIHR) Collaboration for Leadership in Applied Health Research and Care (CLAHRC) for Cambridgeshire and Peterborough at Cambridgeshire and Peterborough NHS Foundation Trust. The views expressed are those of the authors and not necessarily those of the NHS, the NIHR or the Department of Health. We are grateful for the administrative support of Angela Harper. GC is the guarantor.

Dr Gemma Clarke was funded by was funded by the University of Cambridge and the NIHR (National Institute of Heath Research) CLAHRC (Collaborations for Leadership in Applied Health Research and Care) East of England. Dr Simon Johnston was funded by the University of Cambridge and the Wellcome Trust. Dr Pippa Corrie was funded by the Cambridge University Hospitals NHS Foundation Trust. Ms. Isla Kuhn was funded by the University of Cambridge Library. Dr Stephen Barclay was funded by the University of Cambridge and the NIHR (National Institute of Heath Research) CLAHRC (Collaborations for Leadership in Applied Health Research and Care) East of England. The authors' funding bodies had no role in: the design of the study; the collection, analysis, or interpretation of the data; the writing of the manuscript; nor the decision to submit for publication.

\section{Transparency declaration}

This manuscript is an honest, accurate, and transparent account of the study being reported; that no important aspects of the study have been omitted; and that any discrepancies from the study as planned (and, if relevant, registered) have been explained.

\section{Author details}

${ }^{1}$ Primary Care Unit, Department of Public Health and Primary Care, University of Cambridge, Cambridge, United Kingdom. ${ }^{2}$ Carroll Lab Cambridge Research Institute, Cancer Research UK Cambridge Research Institute, Cambridge, United Kingdom. ${ }^{3}$ Department of Oncology, University of Cambridge, Cambridge, United Kingdom. ${ }^{4}$ Medical Library, University of Cambridge, Cambridge, United Kingdom.

Received: 17 February 2015 Accepted: 27 October 2015 Published online: 11 November 2015

\section{References}

1. WHO: National cancer control programmes: policies and managerial guidelines. In., Second Edition edn. Geneva: World Health Organisation; 2002.

2. Earle C. Identifying potential indicators of the quality of end-of-life cancer care from administrative data. J Clin Oncol. 2003;21(6):1133-8. 
3. Cherny N, Catane R, Kosmidis P. ESMO takes a stand on supportive and palliative care. Ann Oncol. 2003;14(9):1335-7.

4. Peppercorn J, Smith T, Helft P, Debono D, Berry S, Wollins D, et al. American society of clinical oncology statement: toward individualized care for patients with advanced cancer. J Clin Oncol. 2011;29(6):755-60.

5. Earle C, Neville B, Landrum M, Ayanian J, Block S, Weeks J. Trends in the aggressiveness of cancer care near the end of life. J Clin Oncol. 2004;15(22):315-21.

6. Warren J, Barbera L, Bremner K, Robin-Yabroff K, Hoch JS, Barrett M, et al. End-of-Life Care for Lung Cancer Patients in the United States and Ontario. J Natl Cancer Inst. 2011;103(11):853-62.

7. Zdenkowski N, Cavenagh J, Ku Y, Bisquera A, Bonaventura A. Administration of chemotherapy with palliative intent in the last 30 days of life: The balance between palliation and chemotherapy. Intern Med J. 2013:43(11):1191-8.

8. Temel JS, McCannon J, Greer J, Jackson V, Ostler P, Pirl W, et al. Aggressiveness of care in a prospective cohort of patients with advanced NSCLC. Cancer. 2008;113(4):826-33.

9. Mort D, Lansdown M, Smith N, Protopapa K, Mason M. For better, for worse? A review of the care of patients who died within 30 days of receiving systemic anti-cancer therapy. In. London: National Confidential Enquiry into PatientOutcome and Death; 2008.

10. Wright A, Zhang B, Keating N, Weeks J, Prigerson H. Associations between palliative chemotherapy and adult cancer patients' end of life care and place of death: propsective cohort study. BMJ. 2014;348:G1219.

11. Rabow M. Chemotherapy near the end of life. BMJ. 2014;348:91529.

12. Li J, Chen F, Cona M, Feng Y, Himmelreich U, Oyen R, et al. A review on various targeted anticancer therapies. Target Oncol. 2012;7(1):69-85.

13. de Bono J, Ashworth A. Translating cancer research into targeted therapeutics. Nature. 2010;467(7315):543-9.

14. Widakowich C, Jr GC, Azambuja E, Dinh P, Awada A. Review: side effects of approved molecular targeted therapies in solid cancers. Oncologist. 2007;12(12):1443-55.

15. Arora A, Scholar EM. Role of Tyrosine Kinase Inhibitors in Cancer Therapy. J Pharmacol Exp Ther. 2005;315(3):971-9.

16. Hirsch F, Mok T, Bunn-Jr P. Molecularly targeted therapy: when to stop and when to continue? Lancet Oncol. 2010;11(8):709-11.

17. Bethune $G$, Bethune D, Ridgway N, Xu Z. Epidermal growth factor receptor (EGFR) in lung cancer: an overview and update. J Thorac Dis. 2010;2:48-51.

18. Mok T, Wu Y-I, Thongprasert S, Yang C, Chu D, Saijo N, et al. Initial treatment of pulmonary adenocarcinoma with gefitinib or carboplatin/paclitaxel. N Engl J Med. 2009;361:947-57.

19. Ou S, Janne P, Bartlett C, Tang Y, Kim D, Otterson G, et al. Clinical benefit of continuing ALK inhibition with crizotinib beyond initial diseae progression in patients with advance ALK-positive NSCLC. Ann Oncol. 2014;25(2):415-22.

20. Chapman P, Hauschild A, Robert C, Haanen J, Ascierto P, Larkin J, et al. Improved Survival with Vemurafenib in Melanoma with BRAF V600E Mutation. NEJM. 2011;364(26):2507-16.

21. Hauschild A, Grob J, Demidov L, Jouary T, Gutzmer R, Millward M, et al. Dabrafenib in BRAF-mutated metastatic melanoma: a multicentre, openlabel, phase 3 randomised controlled trial. Lancet. 2012;380:358-65.

22. Adams VR, Leggas M. Sunitinib Malate for the Treatment of Metastatic Renal Cell Carcinoma and Gastrointestinal Stromal Tumors. Clin Ther. 2007;29(7):1338-53.

23. Motzer RJ, Hutson TE, Tomczak P. Sunitinib versus Interferon Alfa in Metastatic Renal-Cell Carcinoma. N Engl J Med. 2007;356:115-24.

24. Geynisman D. Adherance to Targeted Oral Anticancer Medication. Discov Med. 2013;15(83):231-41.

25. Michaelis LC, Ratain MJ. Measuring response in a post-RECIST world: from black and white to shades of grey. Nat Rev Cancer. 2006;6(5):409-14.

26. Nishida T, Doi T. Rechallenge of drugs in the era of targeted therapy. Lancet Oncol. 2013;14(12):1143-5.

27. Kuczynski EA, Sargent DJ, Grothey A, Kerbel RS. Drug rechallenge and treatment beyond progression-implications for drug resistance. Nat Rev Clin Oncol. 2013;10(10):571-87.

28. Riely G, Kris M, Zhao B, Akhurst T, Milton D, Moore E, et al. Prospective Assessment of Discontinuation and Reinitiation of Erlotinib or Gefitinib in Patients with Acquired Resistance to Erlotinib or Gefitinib Followedby the Additionof Everolimus. Clin Cancer Res. 2007;13(17):5150-5.

29. Blay J, LeCesne A, Ray-Coquard I, Bui B, Duffaud F, Delbaldo C, et al. Prospective Multicentric Randomized Phase III Study of Imatinib in Patients With Advanced Gastrointestinal Stromal Tumors Comparing
Interruption Versus Continuation of Treatment Beyond 1 Year: The French Sarcoma Group. J Clin Oncol. 2007;25(9):1107-13.

30. Blay J, Pérol D, Cesne AL. Imatinib rechallenge in patients with advanced gastrointestinal stromal tumors. Ann Oncol. 2012;23(7):1659-65.

31. Nozawa M, Yamamoto $Y$, Minami T, Shimizu H, Hatanaka Y, Tsuji H, et al. Sorafenib rechallenge in patients with metastatic renal cell carcinoma. BJU Int. 2012;110(6pt B):E228-34.

32. Joint Formulary Committee. British National Formulary (BNF) 67. London: Pharmaceutical Press; 2014.

33. Thomas J, Harden A. Methods for the thematic synthesis of qualitative research in systematic reviews. BMC Med Res Meth. 2008;8(45):1-10.

34. Petticrew M, Roberts H. Systematic Reviews in the Social Science: A Practical Guide. Oxford: Blackwell Publishing; 2006.

35. Liberati A, Altman D, Tetzlaff J, Mulrow C, Gøtzsche P, loannidis J, et al. The PRISMA statement for reporting systematic reviews and meta-analyses of studies that evaluate healthcare interventions: explanation and elaboration. BMJ. 2009;339:b2700.

36. Gough D. Weight of evidence: a framework for the appraisal of the quality and relevance of evidence. Res Pap Educ. 2007:22(2):213-28.

37. Carroll C, Booth A, Lloyd-Jones M. Should we exclude inadequately reported studies from qualitative systematic reviews? An evaluation of sensitivity analyses in two case study reviews. Qual Health Res. 2012;22(10):1425-34.

38. Bluhm MV. Factors Influencing Oncologists' Use of Chemotherapy In Patients At The End Of Life: A Qualitative Study. Michigan: University of Michigan; 2011.

39. Behl D, Jatoi A. What Do Oncologists Say about Chemotherapy at the Very End of Life? Results from a Semiqualitative Survey. J Palliat Med. 2010;13(7):831-5

40. Kort SJ, Pols J, Richel DJ, Koedoot N, Willems DL. Understanding Palliative Cancer Chemotherapy: About Shared Decisions and Shared Trajectories. Health Care Anal. 2010;18(2):164-74.

41. Martoni A, Tanneberger S, Mutri V. Cancer chemotherapy near the end of life: the time has come to set guidelines for its appropriate use. Tumori. 2007:93(5):417-22.

42. Back A, Michaelsen K, Alexander S, Hopley E, Edwards K, Arnold R. How oncology fellows discuss transitions in goals of care: A snapshot of approaches used prior to training. J Palliat Med. 2010;13(4):395-400.

43. McCullough L, McKinlay E, Barthow C, Moss C, Wise D. A model of treatment decision making when patients have advanced cancer: how do cancer treatment doctors and nurses contribute to the process? Eur J Cancer Care (Engl). 2010;19(4):482-91.

44. Harrington S, Smith T. The role of chemotherapy at the end of life: 'when is enough, enough? JAMA. 2008;299(22):2667-78.

45. Meeker M. Responsive Care Management: Family Decision Makers in Advanced Cancer. J Clin Ethics. 2011;22(2):107-22.

46. Ohlén J, Elofsson L, Hydén L, Friberg F. Exploration of communicative patterns of consultations in palliative cancer care. Eur J Oncol Nurs. 2008;12(1):44-52.

47. Sarenmalm EK, Thorén-Jönsson A-L, Gaston-Johansson F, Ohlén J. Making sense of living under the shadow of death: adjusting to a recurrent breast cancer illness. Qual Health Res. 2009:19(8):116-30.

48. Schildmann J, Ritter P, Salloch S, Uhl W, Vollman J. 'One also needs a bit of trust in the doctor ... ': a qualitative interview study with pancreatic cance patients about their perceptions and views on information and treatment decision-making. Ann Oncol. 2013;24(9):2444-9.

49. Schildmann J, Tan J, Salloch S, Vollman J. Well, I think there is great variation...": a qualitative study of oncologists' experiences and views regarding medical criteria and other factors relevant to treatment decisions in advanced cancer. Oncologist. 2013;18(1):90-6.

50. Reinke L, Engleberg R, Shannon S, Wenrich M, Vig E, Back A, et al. Transitions regarding palliative and end-of-life care in severe chronic obstructive pulmonary disease or advanced cancer: themes identified by patients, families, and clinicians. J Palliat Med. 2008;11(4):601-9.

51. Kacen L, Madjar I, Denham J, Ackland S, Ariad S. Patients deciding to forgo or stop active treatment for cancer. Eur J Pall Car. 2005;12(3):113-6.

52. Buiting HM, Rurup ML, Wijsbek $H$, Van-Zuylen L, Den-Hartogh $G$. Understanding provision of chemotherapy to patients with end stage cancer: qualitative interview study. BMJ. 2011:342:d1933.

53. Koedoot C, Oort F, De-Haan R, Bakker P, De-Graeff A, De-Haes J. The content and amount of information given by medical oncologists when telling patients with advanced cancer what their treatment 
options are: Palliative chemotherapy and watchful-waiting. Eur J Cancer. 2004;40(2):225-35.

54. Keam B, Oh D, Lee S, Kim D, Kim M, Im S, et al. Aggressiveness of CancerCare near the End-of-Life in Korea. Jpn J Clin Oncol. 2008;38(5):381-6.

55. Chouliara Z, Miller M, Stott D, Molassiotis A, Twelves C, Kearney N. Older people with cancer: perceptions and feelings about information, decisionmaking and treatment: a pilot study. Eur J Oncol Nurs. 2004;8(3):257-61.

56. Morita T, Akechi T, Ikenaga M, Kizawa $Y$, Kohara $H$, Mukaiyama $T$, et al. Communication about the ending of anticancer treatment and transition to palliative care. Ann Oncol. 2004;15(10):1551-7.

57. Hashimoto K, Yonemori K, Katsumata N, Hotchi M, Kouno T, Shimizu C, et al. Factors That Affect the Duration of the Interval Between the Completion of Palliative Chemotherapy and Death. Oncologist. 2009;14(7):752-9.

58. Maida V, Peck J, Ennis M, Brar N, Maida AR. Preferences for active and aggressive intervention among patients with advanced cancer. BMC Cancer. 2010;10:592.

59. Brearley S, Craven O, Saunders M, Swindell R, Molassiotis A. Clinical features of oral chemotherapy: results of a longitudinal prospective study of breast and colorectal cancer patients receiving capecitabine in the UK. Eur J Cancer Care (Engl). 2010;19(4):425-33.

60. Andreis F, Rizzi A, Rota L, Meriggi F, Mazzocchi M, Zaniboni A. Chemotherapy use at the end of life. A retrospective single centre experience analysis. Tumori. 2011;97(1):30-4.

61. Andrew J, Whyte $F$. The experiences of district nurses caring for people receiving palliative chemotherapy. Int J Palliat Nurs. 2004;10(3):110-8.

62. Liu T, Chang W, Wang H, Chen J, Koong S, Hsiao S, et al. Use of chemotherapy at the end of life among Taiwanese cancer decedents. Acta Oncol. 2012;51(4):505-11.

63. Voogt E, Van-der-Heide A, Rietjens J, Van-Leeuwen A, Visser A, Van-der-Rit C, et al. Attitudes of patients with incurable cancer toward medical treatment in the last phase of life. J Clin Oncol. 2005;23(9):2012-9.

64. Hui D, Karuturi M, Tanco K, Kwon J, Kim S, Zhang T, et al. Targeted Agent Use in Cancer Patients at the End of Life. J Pain Symptom Manage. 2013;46(1):1-8.

65. Wong $Y$, Ottensen $R$, Hughes $M$. Continued use of trastuzumab beyond disease progression in the national comprehensive cancer network: should we practice ahead of the evidence? Oncologist. 2011;16(5):559-65.

66. Kao S, Shafiq J, Vardy J, Adams D. Use of chemotherapy at end of life in oncology patients. Ann Oncol. 2009;20(9):1555-9.

67. Emanuel E, Young-Xu Y, Levinsky N, Gazelle G, Sayina O, Ash A. Chemotherapy Use among Medicare Beneficiaries at the End of Life. Ann Intern Med. 2003;138(8):639-43.

68. Koedoot C, Haan R, Stiggelbout A, Stalmeier P, De-Graeff A, Bakker P, et al. Palliative chemotherapy or best supportive care? A prospective study explaining patients' treatment preference and choice. Br J Cancer. 2003:89(12):2219-26.

69. Barthow C, Moss C, McKinlay E, McCullough L, Wise D. To be involved or not: Factors that influence nurses' involvement in providing treatment decisional support in advanced cancer. Eur J Oncol Nurs. 2009;13(1):22-8.

70. Rose J, OToole E, Dawson N, Lawrence R, Gurley D, Thomas C, et al. Perspectives, preferences, care practices, and outcomes among older and middle-aged patients with late-stage cancer. J Clin Oncol. 2004;22(24):4907-17.

71. Coulehan J. "They wouldn't pay attention": Death without dignity. Am J Hosp Palliat Care. 2005;22(5):339-43.

72. Penson R, Dignan F, Seiden M, Lee H, Gallagher C, Matulonis U, et al. Attitudes to chemotherapy in patients with ovarian cancer. Gynecol Oncol. 2004;94(2):427-35.

73. Zhang AY, Zyzanski SJ, Siminoff LA. Ethnic differences in the caregiver's attitudes and preferences about the treatment and care of advanced lung cancer patients. Psychooncology. 2012;21(11):1250-3.

74. Weeks JC, Catalano PJ, Cronin A, Finkelman M, Mack J, Keating N, et al. Patients' expectations about effects of chemotherapy for advanced cancer. N Engl J Med. 2012;367(17):1616-25.

75. Earle C, Landrum M, Souza J, Neville B, Weeks J, Ayanian J. Aggressiveness of cancer care near the end of life: is it a quality-of-care issue? J Clin Oncol. 2008;26(23):3860-6.

76. Yun Y, Kwak M, Park S, Kim S, Choi J, Lim H, et al. Chemotherapy use and associated factors among cancer patients near the end of life. Oncology. 2007;72(3-4):164-7.

77. Colla C, Morden N, Skinner J, Hoverman J, Meara E. Impact of Payment Reform on Chemotherapy at the End of Life. Am J Manag Care. 2012;18(5):e200-8.
78. Pardon K, Deschepper R, Vander-Stichele R, Bernheim J, Mortier F, Schallier $D$, et al. Preferred and actual involvement of advanced lung cancer patients and their families in end-of-life decision making: a multicenter study in 13 hospitals in Flanders, Belgium. J Pain Symptom Manage. 2012:43(3):515-26.

79. Bakitas M, Ahles TA, Skalla K, Brokaw F, Byock I, Hanscom B, et al. Proxy Perspectives about End-of-Life Care for Person's with Cancer. Cancer. 2008;112(8):1854-61.

80. Volker D, Wu H. Cancer patients' preferences for control at the end of life. Qual Health Res. 2011;21(12):1618-31.

81. Cancer Research UK. Chemotherapy side effects [http:// www.cancerresearchuk.org/about-cancer/cancers-in-general/treatment/ chemotherapy/chemotherapyside-effects. Accessed 5 November 2015.

82. Carelle N, Piotto E, Bellanger A, Germanaud J, Thuillier A, Khayat D. Changing Patient Perceptions of the Side Effects of Cancer Chemotherapy. Cancer. 2002;95(1):155-63.

83. Force T, Krause DS, Etten RAV. Molecular mechanisms of cardiotoxicity of tyrosine kinase inhibition. Nat Rev Cancer. 2007:7(5):332-44.

84. Mattei P, Alora-Palli M, Kraft S, Lawrence D, Flaherty K, Kimball A. Cutaneous effects of BRAF inhibitor therapy: a case series. Ann Oncol. 2013;24(2):530-7.

85. Ommen $\mathrm{O}$, Thuem S, Pfaff $\mathrm{H}$, Janssen $\mathrm{C}$. The relationship between social support, shared decision-making and patient's trust in doctors: a cross-sectional survey of 2,197 inpatients using the Cologne Patient Questionnaire. Int J Public Health. 2011;56(3):319-27.

86. Kraetschmer N, Sharpe N, Urowitz S, Deber R. How does trust affect patient preferences for participation in decision-making? Health Expect. 2004;7:317-26.

\section{Submit your next manuscript to BioMed Central and take full advantage of:}

- Convenient online submission

- Thorough peer review

- No space constraints or color figure charges

- Immediate publication on acceptance

- Inclusion in PubMed, CAS, Scopus and Google Scholar

- Research which is freely available for redistribution 